\title{
Aggressiveness Variation among and within Fusarium Head Blight Species on Barley in vitro
}

\author{
N. SAKR \\ Department of Agriculture, Atomic Energy Commission of Syria (AECS), Damascus, P.O. Box 6091, Syria
}

(Received: 27 July 2017; accepted: 19 September 2017)

\begin{abstract}
Aggressiveness variation among 16 isolates of four Fusarium species (F. culmorum, F. solani, F. verticillioides and F. equiseti) causing Fusarium head blight (FHB) was studied in vitro. Evaluation of three aggressiveness criteria involved in a Petri-dish test: germination rate reduction, standardized area under disease progress curve $\left(\mathrm{AUDPC}_{\text {standard }}\right)$, and coleoptile length reduction was carried out on the barley cultivar Arabi Aswad. Results showed differences between barley plants inoculated with FHB isolates and control for the three tested aggressiveness criteria. Regarding AUDPC $_{\text {standard }}$ and Petri-dish aggressiveness index which is calculated from the mean value of three aggressiveness criteria, within and among variation was detected. Intra- and inter-species variability was not distinguished for the other two aggressiveness criteria. However, pathogenic level observed among 16 isolates can not be differentiated within the four FHB species. Significant correlation was detected only between AUDPC $_{\text {standard }}$ and Petri-dish aggressiveness index. The results were comparable with those previously obtained using the same fungal isolates on wheat cultivar in vitro. It seems that FHB isolates recovered from wheat spikes and tested on wheat plants showed a similar range of aggressiveness on a barley cultivar, Arabi Aswad.
\end{abstract}

Keywords: Barley cultivar, FHB species, in vitro test, pathogenic variation.

Fusarium head blight (FHB) is one of the most important diseases of barley, wheat and other small grain crops worldwide. FHB infection occurs primarily during the flowering of the crop and shortly afterward when humid conditions and moderate temperatures prevail. Bleached spike appearance due to premature death of tissues is a typical symptom of FHB in infected plants. Diseased spikes are sterile or contain discolored and shriveled seeds (Parry et al., 1995). This disease known to impact significantly upon the yield causing dramatic economic losses of up to 50\% (Parry et al., 1995; McMullen et al., 2012). Also, FHB reduces grain quality by producing mycotoxins during fungal colonization such as deoxynivalenol and nivalenol, which presents a major potential risk to both humans and animals (Maresca, 2013). Several functional parameters of grain related to malting and brewing quality were severely influenced by mycotoxin contamination (Nielsen et al., 2014).

FHB is caused by at least seventeen species within the Fusarium genus. Fusarium graminearum is reported as the most prominent species in barley. Also, other FHB causal agents are isolated frequently from FHB infected kernels (McCallum and Tekauz, 2002;

* Corresponding author; e-mail: ascientific@aec.org.sy 
Xue et al., 2005; Bilikova and Hudec, 2014; Ovsyankina et al., 2016). The pathogenic level revealed that $F$. crookwellense, $F$. culmorum and $F$. graminearum are highly pathogenic, $F$. avenaceum is moderately pathogenic, and $F$. equiseti, $F$. poae and $F$. sporotrichioides are weakly pathogenic (Xue et al., 2005). Environmental factors, agricultural practices and cultivar susceptibility play an important role in pathogenesis (Doohan et al., 2003).

Fundamental characterization of aggressiveness of a FHB species, the extent to which it can attack a susceptible host, explains the interaction between FHB populations and barley. Also, comprehension of the aggressiveness variability is crucial for disease management (Xue et al., 2005). Resistance of barley to FHB is a character controlled by a polygenic system (quantitative trait loci detected on all chromosomes), with no clear evidence for host by pathogen species interaction (Steffenson, 2003). For a given FHB species, aggressiveness of different isolates may vary, with the more aggressive ones affecting barley plants faster and/or more intensively. Several reports have underlined a significant variation for aggressiveness in FHB causal agents on barley plants (McCallum and Tekauz, 2002; Xue et al., 2005; Bilikova and Hudec, 2014; Ovsyankina et al., 2016). Floret inoculation in adult plants in a growth chamber and in the field represents the traditional evaluation of FHB aggressiveness on barley plants (Imathiu et al., 2014). However, in vitro assays for prescreening FHB aggressiveness has been gained little attention as compared with wheat such as: seedling test (Hestbjerg et al., 2002), and detached leaf assay (Opoku et al., 2011). Whether FHB isolates recovered from barley and wheat show similar agressiveness lack specialization in their hosts is not clear since most studies focus on single measurement of aggressiveness in a specific host. The pathogenicity of Fusarium spp. on barley may be or not the same as on wheat (McCallum and Tekauz, 2002; Xue et al., 2005).

In Syria, barley cultivation up to 1262000 hectares is distributed in marginal environments where severe drought, thermal stress and spatial and temporal variations in rainfall are prevailing. Barley is mostly used for livestock feed with less than one million tones in 2013. Syrian farmers predominantly grow one cultivar Arabi Aswad, it is largely adapted to drier areas (Bishawa et al., 2015). There are no reports about the presence of FHB on barley in Syria, but Fusarium species are present and frequently isolated in wheat cultivated areas (Alazem, 2007). Sakr (2017b) used an in vitro approach adapted by Purahong et al., (2012) to analyse pathogenic variation in FHB isolates recovered from wheat kernels, and he found significant differences between pathogen isolates and wheat cultivars. Also, floret inoculations data under controlled conditions were comparable with those obtained in vitro (Sakr, 2017a). In order to better understand the pathogenic variation in Syrian FHB species complex on barley plants, the objectives of the current research were to (i) investigate variability within four FHB species (F. culmorum, F. solani, $F$. verticillioides and $F$. equiseti) in vitro, and (ii) determine whether or not the observed variability can be used to differentiate the FHB species. 


\section{Materials and Methods}

\section{Fungal isolates and barley cultivar}

Sixteen fungal isolates of four Fusarium species (F. culmorum (F1, F2, F3, F28 and F30), F. verticillioides (F15, F16, F21 and F27), F. solani (F7, F20, F26, F29, F31 and $\mathrm{F} 35)$, and $F$. equiseti (F43)) were recovered from wheat spikes showing FHB symptoms in 2015. Isolates were identified morphologically according to Nelson et al. (1983). The cultures were maintained in sterile distilled water at $4{ }^{\circ} \mathrm{C}$ and freezing at $-16{ }^{\circ} \mathrm{C}$ until needed.

Barley cultivar Arabi Aswad, largely cultivated in Syria, is characterized with high agricultural criteria under sever climatic conditions, and resistance to fungal diseases. It was used to characterize aggressiveness of 16 FHB isolates.

\section{Aggressiveness tests}

Purahong et al. (2012) adapted a Petri-dish test to quantify aggressiveness in F. graminearum, and this method was used by Sakr (2017b) to analyse aggressiveness in other FHB species on wheat plants. It requires less time (only 6 days for the whole experiment), and in vitro data were comparable with the floret inoculations (Purahong et al., 2012; Sakr, 2017a). In the current study, this method was conducted to characterize aggressiveness of 16 FHB isolates.

Sterilized barley seeds for Arabi Aswad were inoculated with a suspension of conidia at $1 \times 10^{6}$ conidia per $\mathrm{ml}$ (or sterile distilled water in the control treatment) for 16 fungal isolates in Petri-dishes with sterile double-layer filter paper. Three aggressiveness criteria: germination rate reduction, standardized area under disease progress curve $\left(\mathrm{AUDPC}_{\text {standard }}\right)$, and coleoptile length reduction were evaluated. Three replicates of each isolate were set up, and the experiment was repeated. Infected and control treatments were incubated in an incubator at $22{ }^{\circ} \mathrm{C}$ in the dark. Germination rate reduction and coleoptile length reduction were determined by comparison with the control treatment at 6 days after inoculation. The value of $\mathrm{AUDPC}_{\text {standard }}$ ranges from 0 (not aggressive) to 1 (very aggressive), and it is calculated from the percentage of healthy coleoptiles as a function of time (from 2 to 6 days after inoculation). Petri-dish index calculated from the mean value of three aggressiveness criteria linked with aggressiveness of fungal isolates.

\section{Statistical analyses}

Statistical analyses of aggressiveness data were performed using StatView, $4.57^{\circledR}$ Abacus Concepts, Berkley, Canada. Before statistical analysis, the percentages were transformed using the Arcsines function. A complete randomized design with one factor (Fusarium isolate) and 3 replications was used for aggressiveness analysis. Fisher's LSD test was used to compare the means at $\mathrm{P}=0.05$. The sample correlation coefficients (Pearson $r$ ) were calculated using overall mean values per isolates at $\mathrm{P}=0.05$ and $\mathrm{P}=0.01$. 


\section{Results and Discussion}

Because of costly, time consuming, laborious work in the floret inoculation assay under controlled and field conditions (Imathiu et al., 2014), in vitro assay has a high potential to facilitate the analysis of aggressiveness in several phytopathogenic species of the genus Fusarium. With this in mind, the variation of quantitative component of pathogenicity was analysed for four Fusarium head blight (FHB) species using a Petri-dish test adapted by Purahong et al., (2012) on a barley cultivar Arabi Aswad widely cultivated in Syrian provinces. Indeed, Sakr (2017b) quantified the aggressiveness of four FHB isolates on six wheat cultivars and Sakr (unpublished data) analysed pathogenic variation in 16 fungal isolates on wheat cultivar Cham7 using a Petri-dish test adapted by Purahong et al. (2012). However, in the current study, a barley cultivar Arabi Aswad showing a high level of quantitative resistance was used to underline variation of aggressiveness of 16 fungal isolates of four FHB species (previously analysed by Sakr (unpublished data) on wheat).

Intra- and inter-differences in aggressiveness of four Fusarium species (F. culmorum, $F$. verticillioides, $F$. solani, and $F$. equiseti) are indicated when isolates vary in the amount of damage that they cause in barley plants. All the 16 isolates of four Fusarium species caused brown spots on the coleoptiles and/or by mycelium completely covering the seeds, typical in vitro FHB symptoms (Purahong et al., 2012, Sakr, 2017b), in the inoculated Arabi Aswad barley plants, whereas the control plants did not exhibit any symptoms (Fig. 1).

Differences between barley plants inoculated with fungal isolates and control were shown for three tested aggressiveness criteria: germination rate reduction, standardized area under disease progress curve (AUDPC ${ }_{\text {standard }}$ ), and coleoptile length reduction (Table 1). This indicates that a modified Petri-dish test (Purahong et al., 2012) conducted on F. graminearum and four FHB species (Sakr, 2017b) can distinguish significant differences between control treatments and barley plants infected with FHB species $(F$. culmorum, F. verticillioides, $F$. solani, and $F$. equiseti). Although the number of germinated seeds reduced significantly in fungal treatments by a fifth compared with the control ranging from 19 to $23 \%$ (Table 1), and the diseased coleoptiles were only one half of mean lengths of healthy coleoptiles that reached $10.1 \mathrm{~mm}$ on Arabi Aswad whatever was the FHB isolate ranging from 55 to $58 \%$ (Table 1), there were no significant differences intraand inter- the four FHB species (Table 1). Our results are in accordance with in vitro previous germination rate reduction and coleoptile length reduction analyses in which those two aggressiveness criteria did not distinguish FHB isolates (Sakr, 2017b). Also, our results regarding germination rate reduction correspond to those reported by Purahong et al. (2012) for F. graminearum, they observed that reductions in germination rate ranged from 0.17 to $0.38 \%$ were not significant to differentiate among fungal isolates. However, the reduction of the coleoptile length caused by $F$. graminearum reported by Brennan et al. (2003) has been related to aggressiveness. Purahong et al. (2012) found that this parameter distinguished $F$. graminearum isolates. The values of $\mathrm{AUDPC}_{\text {standard }}$ (from 0.22 for 0.45) underlined a variation in aggressiveness within and among four FHB species (Table 1). Our results are comparable with those found by Purahong et al. (2012) and Sakr

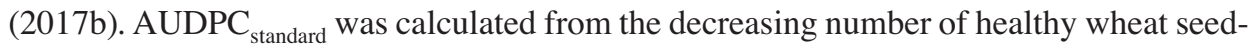




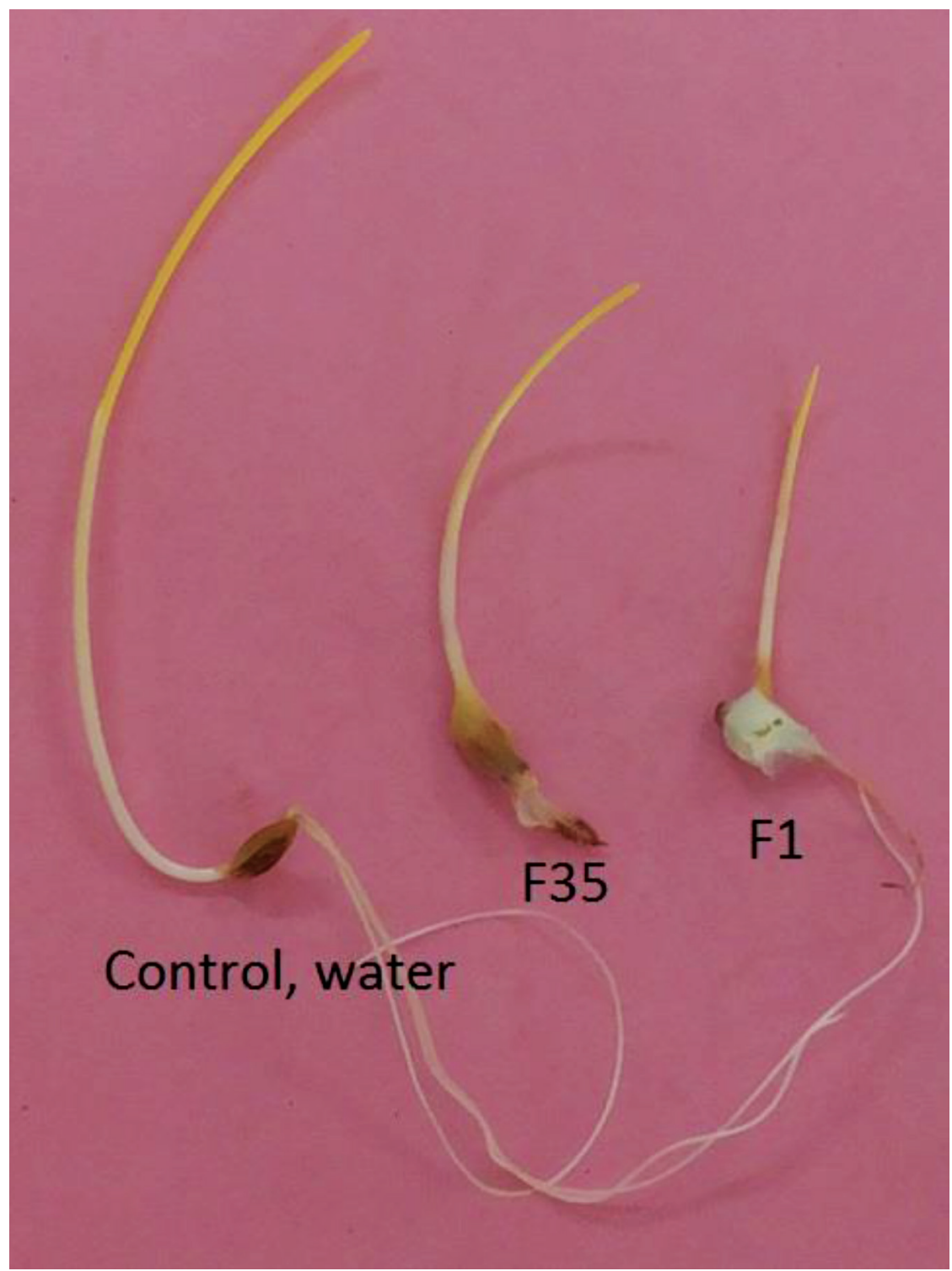

Fig. 1. Symptoms on seedlings of inoculated barley cultivar Arabi Aswad with isolate F1 (Fusarium culmorum) and F35 (F. solani) compare with control (water) at 6 days after inoculation

lings after fungal inoculation of the seeds (Purahong et al., 2012). The faster the reduction of the number of healthy seedlings, the more aggressive is the fungal isolate (Purahong et al., 2012). Our results indicated that the same fungal isolates tested previously on wheat cultivar Cham7 and barley cultivar Arabi Aswad behave similar pathogenic reaction regarding the three analysed aggressiveness criteria. Petri-dish aggressiveness index ranged 
one fold within and among four FHB species (Table 1), and significantly differences in isolates were due to variability in $\mathrm{AUDPC}_{\text {standard }}$ parameter. However, for $25 \mathrm{~F}$. graminearum isolates, Purahong et al. (2012) found that Petri-dish aggressiveness index varied four folds, and for 16 FHB isolates, Sakr (unpublished data) found that it varied one fold.

\section{Table 1}

Aggressiveness within and among four Fusarium head blight species measured on barley cultivar Arabi Aswad

\begin{tabular}{|c|c|c|c|c|}
\hline $\begin{array}{l}\text { Fungal isolates } \\
\text { (identification) }\end{array}$ & $\begin{array}{c}\text { Germination } \\
\text { rate reduction }(\%)\end{array}$ & AUDPCstandard & $\begin{array}{l}\text { Coleoptile length } \\
\text { reduction } \\
(\%)\end{array}$ & $\begin{array}{c}\text { Petri-dish } \\
\text { aggressiveness } \\
\text { index }\end{array}$ \\
\hline F1 (F. culmorum) & 22 & $0.22 \mathrm{~b} \mathrm{E}$ & 57 & $0.34 \mathrm{ABC}$ \\
\hline F2 (F. culmorum) & 21 & $0.29 \mathrm{ab}$ CDE & 56 & $0.35 \mathrm{BC}$ \\
\hline F3 (F. culmorum) & 20 & $0.39 \mathrm{a} A B$ & 58 & $0.39 \mathrm{AB}$ \\
\hline F28 (F. culmorum) & 22 & $0.29 \mathrm{ab} C D E$ & 55 & $0.35 \mathrm{AB}$ \\
\hline \multirow[t]{3}{*}{ F30 (F. culmorum) } & 23 & $0.34 \mathrm{ab}$ BCD & 56 & $0.38 \mathrm{ABC}$ \\
\hline & $\mathrm{F}=0.232 \mathrm{~ns}$ & $\mathrm{~F}=2.300$ & $\mathrm{~F}=0.133 \mathrm{~ns}$ & $\mathrm{~F}=0.0803 \mathrm{~ns}$ \\
\hline & $\mathrm{P}=0.9143$ & $\mathrm{P}=0.1302$ & $\mathrm{P}=0.9668$ & $\mathrm{P}=0.5503$ \\
\hline F7 (F. solani) & 20 & $0.45 \mathrm{a} \mathrm{A}$ & 56 & $0.45 \mathrm{a} \mathrm{A}$ \\
\hline F20 (F. solani $)$ & 23 & $0.40 \mathrm{ab} \mathrm{AB}$ & 56 & $0.46 \mathrm{a} \mathrm{AB}$ \\
\hline F26 (F. solani $)$ & 20 & $0.39 \mathrm{abc} \mathrm{AB}$ & 57 & $0.42 \mathrm{ab} \mathrm{AB}$ \\
\hline F29 (F. solani) & 20 & $0.38 \mathrm{bc} \mathrm{ABC}$ & 55 & $0.38 \mathrm{~b}$ ABC \\
\hline F31 (F. solani) & 20 & $0.33 \mathrm{c} \mathrm{BCD}$ & 55 & $0.42 \mathrm{ab} \mathrm{ABC}$ \\
\hline \multirow[t]{3}{*}{ F35 (F. solani $)$} & 19 & $0.39 \mathrm{abc} \mathrm{AB}$ & 55 & $0.41 \mathrm{ab} \mathrm{ABC}$ \\
\hline & $\mathrm{F}=0.176 \mathrm{~ns}$ & $\mathrm{~F}=2.904$ & $\mathrm{~F}=0.123$ & $\mathrm{~F}=2.295$ \\
\hline & $\mathrm{P}=0.9667$ & $P=0.604$ & $\mathrm{P}=0.9844 \mathrm{~ns}$ & $\mathrm{P}=0.1107$ \\
\hline F15 (F. verticillioides) & 21 & $0.22 \mathrm{~b} \mathrm{E}$ & 57 & $0.39 \mathrm{BC}$ \\
\hline F16 (F. verticillioides) & 19 & $0.31 \mathrm{ab} \mathrm{BCDE}$ & 55 & $0.41 \mathrm{ABC}$ \\
\hline F21 (F. verticillioides) & 20 & 0.35 a BC & 55 & $0.43 \mathrm{ABC}$ \\
\hline \multirow[t]{3}{*}{ F27 (F. verticillioides) } & 19 & $0.25 \mathrm{ab} \mathrm{DE}$ & 56 & $0.38 \mathrm{C}$ \\
\hline & $\mathrm{F}=0.371 \mathrm{~ns}$ & $\mathrm{~F}=2.940$ & $\mathrm{~F}=0.175 \mathrm{~ns}$ & $\mathrm{~F}=1.976 \mathrm{~ns}$ \\
\hline & $P=0.7762$ & $\mathrm{P}=0.0989$ & $\mathrm{P}=0.9104$ & $P=0.1963$ \\
\hline F43 (F. equiesti) & 21 & $0.40 \mathrm{AB}$ & 57 & $0.40 \mathrm{AB}$ \\
\hline \multirow[t]{2}{*}{ Enter isolates } & $\mathrm{F}=0.416 \mathrm{~ns}$ & $\mathrm{~F}=4.440$ & $\mathrm{~F}=1.170$ & $\mathrm{~F}=1.266$ \\
\hline & $\mathrm{P}=0.9631$ & $\mathrm{P}=0.0002$ & $\mathrm{P}=0.3417$ & $\mathrm{P}=0.2784$ \\
\hline
\end{tabular}

According to the Fisher's LSD test, means followed by the same letter are not significantly different at $\mathrm{p}=0.05$ (small letters refer to aggressiveness within species and capital letters to aggressiveness between isolates of species), ns = not significant, Probability $(\mathrm{P})$, F-tests $(\mathrm{F})$, Petri-dish aggressiveness index $=($ germination rate

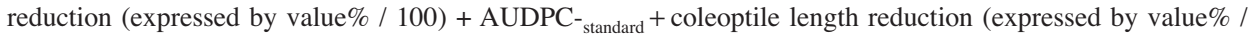
100)) /3 (Purahong et al., 2012). 
Table 2

Correlation coefficients on barley cultivar Arabi Aswad among criteria of aggressiveness for 16 isolates of four Fusarium head blight species

\begin{tabular}{|c|c|c|c|c|}
\hline & $\begin{array}{l}\text { Germination rate } \\
\text { reduction }\end{array}$ & AUDPC $_{\text {standard }}$ & $\begin{array}{l}\text { Coleoptile length } \\
\text { reduction }\end{array}$ & $\begin{array}{c}\text { Petri-dish } \\
\text { aggressiveness } \\
\text { index }\end{array}$ \\
\hline Germination rate reduction & 1.000 & & & \\
\hline AUDPC $_{\text {standard }}$ & $-0.129 \mathrm{~ns}$ & 1.000 & & \\
\hline Coleoptile length reduction & $0.211 \mathrm{~ns}$ & -0.04 & 1.000 & \\
\hline Petri-dish aggressiveness index & $-0.169 \mathrm{~ns}$ & $0.680 * *$ & $-0.100 \mathrm{~ns}$ & 1.000 \\
\hline
\end{tabular}

$* \mathrm{P}=0.05, * * \mathrm{P}=0.01, \mathrm{~ns}=$ no significant.

The three parameters obtained with the Petri dish test were not significantly correlated (Table 2). Significant correlation was detected only between AUDPC $_{\text {standard }}$ and Petri-dish aggressiveness index: $r=0.680 * *$. It seems that mechanisms underlying these three aggressiveness criteria did not share the same genetic background. Our results correspond with those found by Sakr (unpublished data) in which the three aggressiveness parameters obtained with the Petri dish test were not significantly correlated. However, our results are not in accordance with those obtained by Purahong et al. (2012); they found significant correlations among the four aggressiveness parameters used in the present research: germination rate reduction, standardized area under disease progress curve (AUDPC $_{\text {standard }}$, coleoptile length reduction, Petri-dish aggressiveness index.

High germination rate reduction, high $\mathrm{AUDPC}_{\text {standard }}$ values, and significant reduction in the length of the coleoptile represent high aggressiveness (Purahong et al., 2012). Results shown in Table 1 indicated that AUDPC $_{\text {standard }}$ parameter can underline within and among variation of aggressiveness in four FHB species. Within F. culmorum species, the lowest AUDPC $_{\text {standard }}$ value (0.22) occurred for F1, whereas the most aggressive isolate F3, with value (0.39). Within F. solani species, the least $\mathrm{AUDPC}_{\text {standard }}$ value was for F31 (0.33), and the most aggressive isolate was F7 (0.45). Within F. verticillioides species, F15 gave the least $\operatorname{AUDPC}_{\text {standard }}(0.22)$, while F21 (0.35) was significantly more aggressive. Our results are comparable with those found by Sakr (unpublished data) in which significant differences were detected in vitro on wheat plants within three FHB species $F$. culmorum, $F$. solani, and $F$. verticillioides. There were significant differences in the variability of aggressiveness among the isolates from the four FHB species, the isolate $\mathrm{F} 7$ ( $F$. solani) showed the greatest aggressiveness, while F1 (F. culmorum) and F15 (F. verticillioides) were the least aggressive isolates (Table 1). It is clear that variations in Petri-dish aggressiveness index were due to variations in $\mathrm{AUDPC}_{\text {standard }}$ parameter, and within and among variability of aggressiveness in four FHB species was nearly similar to AUDPC $_{\text {standard }}$ values, except for intra- F. culmorum and F. verticillioides species in 
which Petri-dish aggressiveness index did not give significant differences. However, the AUDPC $_{\text {standard }}$ differences among 16 isolates can not be used to differentiate between the four FHB species, for example, isolates F3 and F30 (F. culmorum), F20, F26, and F35 (F. solani), F16 and F21 (F. verticillioides), and F43 (F. equiseti) were not significantly different (Table 1). Sakr (unpublished data) hypothesized that geographic origin of FHB isolates plays a crucial role in increasing the level of pathogenic similarity between fungal species. More interestingly, our results confirmed that FHB isolates recovered from wheat spikes and tested on wheat cultivar Cham7 (Sakr, unpublished data) showed similar range of aggressiveness on barley cultivar Arabi Aswad $(r=0.584 *)$. Similar range of aggressiveness in cross-species pathogenicity test was reported in association between FHB populations and wheat and maize host plants (Kuhnem et al., 2015).

It is widely accepted that the level of FHB resistance in wheat is less than in barley (Steffenson, 2003). Our results showed that wheat cultivar Cham7 exhibited a higher AUDPC $_{\text {standard }}$ (Sakr, unpublished data) than barley cultivar Arabi Aswad using the same

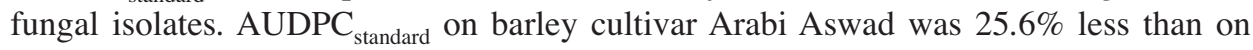
wheat cultivar Cham7 (Sakr, unpublished data). Thus, the current study provides evidence that Arabi Aswad is more resistant than Cham7. High level of quantitative resistance in Arabi Aswad made it possible to detect intra- and inter-significant differences (Table 1). These results are in accordance with previous analysis on the good level of resistance for Arabi Aswad against common root rot (Cochliobolus sativus) (van Leur et al., 1997) and leaf blotch caused by the fungus Rhynchosporium secalis (Abang et al., 2006). Arabi Aswad could be considered as promising resistance sources to FHB for introgression in the adapted barley gene pool.

\section{Conclusion}

The current research provides interesting data regarding the in vitro pathogenic reaction between barley cultivar Arabi Aswad and 16 fungal isolates of four FHB species recovered from wheat kernels. The method described by Purahong et al. (2012) for F. graminearum on wheat could be conducted also in other FHB agents on barley plants. AUDPC $_{\text {standard }}$ parameter did distinguish variation of aggressiveness for isolates within and among species, and the other two parameters did not. Mechanisms underlying three aggressiveness criteria could not share the same genetic background. The high level of quantitative resistance in Arabi Aswad permitted to underline intra- and inter-species variability. It will be necessary to analyse the pathogenic reaction of the fungal isolates recovered from naturally infected barley plants on Syrian barley cultivars using in vitro techniques and floret inoculation assay under controlled and field conditions to screen levels of resistance in Syrian barley cultivars.

\section{Acknowledgements}

The author would like to thank Director General of AECS, and the Head of the Agriculture Department for their support. 


\section{Literature}

Abang, M. M., Baum, M., Ceccarelli, S., Grando, S., Linde, C. C., Yahyaoui, A., Zhan, J. and McDonald, B. A. (2006): Differential selection on Rhynchosporium secalis during parasitic and saprophytic phases in the barley scald disease cycle. Phytopathology 96, 1214-1222.

Alazem, M. (2007): Evaluating genetic variation of Fusarium head blight by molecular markers. [Dissertation]. [Damascus: DAM], University of Damascus.

Bilikova, J. and Hudec, K. (2014): Occurrence of Fusarium head blight of barley in Slovakia. J. Cent. Eur. Agr. $15,175-184$.

Bishawa, Z., Struikb, P. C. and van Gastelc, A. J. G. (2015): Wheat and barley seed system in Syria: How diverse are wheat and barley varieties and landraces from farmer's fields? Int. J. Plant Prod. 9, 117-150.

Brennan, J. M., Fagan B., van Maanen, A., Cooke, B. M. and Doohan, F. M. (2003): Studies on in vitro growth and pathogenicity of European Fusarium fungi. Eur. J. Plant Pathol. 109, 577-587.

Doohan, F. M., Brennan, F. M. and Cooke, B. M. (2003): Influence of climatic factors on Fusarium species pathogenic to cereals. Eur. J. Plant Pathol. 109, 755-768.

Hestbjerg, H., Felding, G. and Elmholt, S. (2002): Fusarium culmorum infection of barley seedlings: correlation between aggressiveness and deoxynivalenol content. J. Phytopathol. 150, 308-312.

Imathiu, S., Edwards, S., Ray, R. and Back, M. (2014): Artificial inoculum and inoculation techniques commonly used in the investigation of Fusarium head blight in cereals. Acta Phytopathol. et Entomol. Hung. 49, 129-139.

Kuhnem, P. R., Del Ponte, E. M., Dong, Y. and Bergstrom, G. C. (2015): Fusarium graminearum isolates from wheat and maize in New York show similar range of aggressiveness and toxigenicity in cross-species pathogenicity tests. Phytopathology 105, 441-448.

Maresca, M. (2013): From the gut to the brain: journey and pathophysiological effects of the food-associated trichothecene mycotoxin deoxynivalenol. Toxins 5, 784-820.

McCallum, B. D. and Tekauz, A. (2002): Influence of inoculation method and growth stage on Fusarium head blight in barley. Can. J. Plant Pathol. 24, 77-80.

McMullen, M., Bergstrom, G., De Wolf, E., Dill-Macky, R., Hershman, D., Shaner, G. and Van Sanford, D. (2012): A unified effort to fight an enemy of wheat and barley: Fusarium head blight. Plant Dis. 96, 1712-1728.

Nelson, P. E., Toussoun, T. A. and Marasas, W. F. O. (1983): Fusarium Species: An Illustrated Manual for Identification. The Pennsylvania State Univ. Press, Pennsylvania, pp. 1-193.

Nielsen, L. K., Cook, D. J., Edwards, S. G. and Ray, R. V. (2014): The prevalence and impact of Fusarium head blight pathogens and mycotoxins on malting barley quality in UK. Int. J. Food Microbiol. 179, 38-49.

Opoku, N., Back, M. and Edwards, S. G. (2011): Aggressiveness of Fusarium langsethiae isolates towards wheat, barley and oats in an in vitro leaf assay. Plant Breed. Seed Sci. 64, 55-63.

Ovsyankina, A. V., Kolomiets, T. M., Zhemchuzhina, N. S., Glinushkin, A. P. and Kiseleva, M. I. (2016): Some aspects of the distribution of Fusarium on cereals of Russia. Acta Phytopathol. et Entomol. Hung. 51, $183-191$.

Parry, D. W., Jekinson, P. and MCleod, L. (1995): Fusarium ear blight (scab) in small grain cereals - a review. Plant Pathol. 44, 207-238.

Purahong, W., Alkadri, D., Nipoti, P., Pisi, A., Lemmens, M. and Prodi, A. (2012): Validation of a modified Petri-dish test to quantify aggressiveness of Fusarium graminearum in durum wheat. Eur. J. Plant Pathol. 132, 381-391.

Sakr, N. (2017a): Aggressiveness of four Fusarium head blight species on wheat cultivars. Adv. Hortic. Sci. DOI: $10.13128 /$ ahs-20346.

Sakr, N. (2017b): In vitro assessment of Fusarium head blight spp. on wheat cultivars. Arch. Phytopathol. Plant Protect. 50, 254-261.

Steffenson, B. J. (2003): Fusarium head blight of barley: impact, epidemics, management, and strategies for identifying and utilizing genetic resistance. In: K. J. Leonard and W. R. Bushnell (eds): Fusarium Head Blight of Wheat and Barley. American Phytopathological Society, St. Paul, pp. 241-295. 
van Leur, J. A. G., Alamdar, M. Z. and Khawatmi, S. (1997): Effect of common root rot (Cochliobolus sativus) on yields of barley under experimental conditions in northern Syria. Aust. J. Agric. Res. 48, 351-357.

Xue, A. G., Ho, K. M., Butler, G., Vigier, B. J. and Babcock, C. (2005): Pathogenicity of Fusarium species causing head blight in barley. Phytoprotection 87, 55-61. 